\title{
Lipid lowering: statins and the future
}

\author{
James Shepherd
}

Cardiovascular disease (CVD) is the leading cause of death in developed and many developing countries. Between 1970 and 1992 there has been a slow decline in some areas, notably North America, Western Europe, Australia, and New Zealand. ${ }^{1}$ However, CVD mortality has recently increased in Eastern and Central Europe.

A whole spectrum of therapeutic tools is available to manage CVD including thrombolytics, antiplatelet drugs, $\beta$ blockers, angiotensin converting enzyme (ACE) inhibitors, and statins. By using these drugs singly or in combination, CVD risk can be reduced by as much as $50 \%$.

\section{Statin treatment}

1987 was a pivotal year for statins. It was the first year that statin treatment became widely available and the first statin, lovastatin, was marketed in the USA. At the same time the first treatment guidelines were released providing recommendations based on the emerging evidence. $^{23}$ Moreover, there was the first official recognition of the relation between raised cholesterol concentrations and coronary heart disease risk.

At that time there were sceptics who did not believe that lowering cholesterol would have mortality benefits, and some even suggested that lipid lowering drugs could have fatal side effects. Major clinical trials have dispelled these unfounded theories.

In particular there were five major clinical trials looking at lipid lowering with the new statin drugs: 4S, LIPID, CARE, WOSCOPS, and AFCAPS/TexCAPs (fig 1). ${ }^{4-8}$ These studies showed that whatever cardiovascular risk a patient has (ranging from previous myocardial infarction to low plasma cholesterol), they will benefit from cholesterol reduction using statins.

There are a number of different statins available and more are being developed. Interestingly, all of the drugs in this class are different from each other pharmacologically. These pharmacological differences will influence the way in which these agents perform.

\section{Current situation}

Despite the strong evidence highlighting the benefits of lipid lowering, under treatment

Department of
Pathological
Biochemistry,
University of Glasgow,
Galsgow Royal
Infirmary, Alexander
Parade, Glasgow
G31 2ER, UK
J Shepherd
Correspondence to:
Professor Shepherd
email:
jshepherd@gri-biochem.org

Figure 1 The relevance of landmark statin trials to clinical practice.

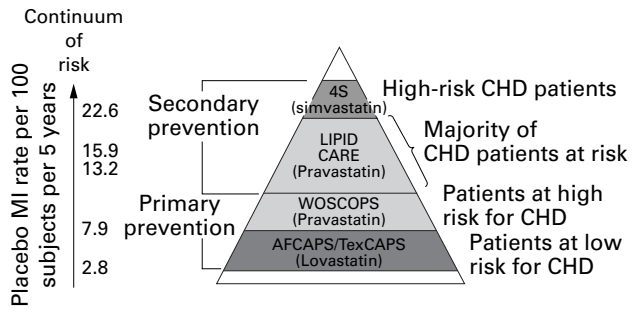

remains an ongoing problem with only one third of eligible patients receiving treatment.

Meanwhile, vascular disease remains a worldwide challenge. Heart disease is a leading cause of premature death and stroke is the leading cause of long term disability. This presents enormous costs to patients, health care systems, and society. Many at risk patients are currently not identified or treated and therefore are not given the opportunity to benefit from a treatment which has proven efficacy.

\section{ANGIOGRAPHIC TRIALS}

The introduction of statins has not only changed the clinical management of patients but has also challenged our understanding of the pathology and treatment of atherosclerotic plaques. Angiographic or ultrasound studies have been designed to demonstrate shrinkage of lesions as a consequence of statin treatment. Results of these trials revealed that all of the drugs produced similar reductions in low density lipoprotein (LDL) cholesterol. There were consistent and significant reductions in clinical events, despite the fact that lesions remained. The clinical benefit therefore eclipsed the angiographic improvement in lumen diameter.

Although angiographic intervention is important because it relieves symptoms, it may not actually reduce the risk of mortality in the long term as it treats lesions that are symptomatic but that do not necessarily lead to fatal occlusion. The lesion of most importance is the relatively small and asymptomatic plaque that might not be seen by angiography (fig 2). However, because of the presence of large amounts of lipid and poor fibrous architecture, a thin fibrous cap and a high level of inflammation it is more likely to rupture. Ideally, the architecture of the lesion should be changed to have a thick fibrous cap, little inflammation, and with a stable architecture that is crisscrossed with collagen.

It may be that statins are doing more than just changing blood cholesterol concentrations, and are, in fact, changing the whole architecture of the plaque.

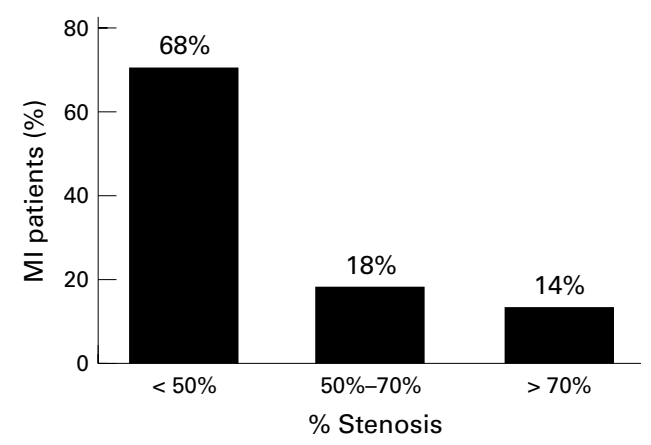

Figure 2 Most myocardial infarctions arise from smaller stenoses. 
Total cholesterol
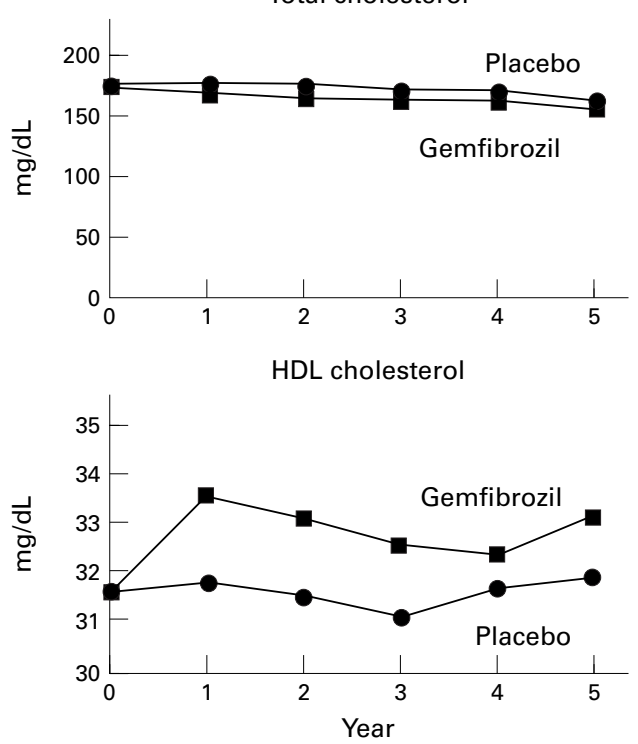

LDL cholesterol
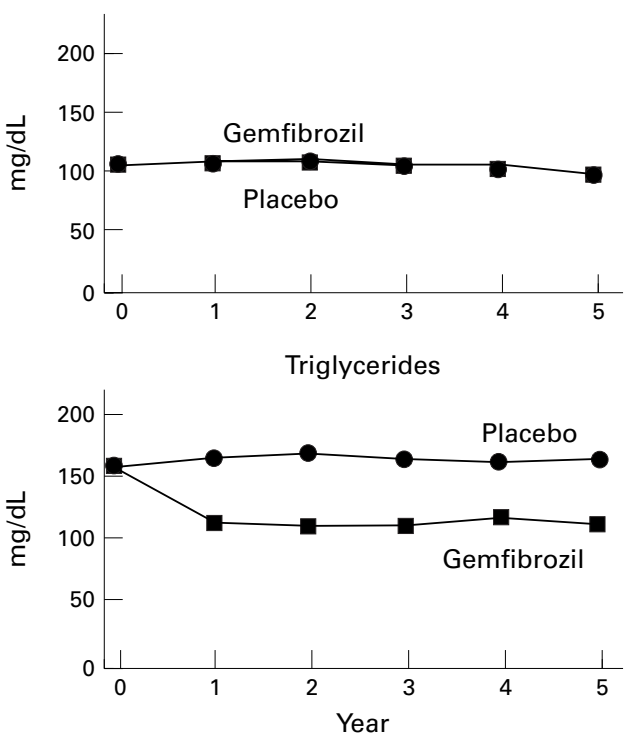

Figure 3 Lipid concentrations in response to treatment with gemfibrozil.

STABILISATION OF THE ATHEROSCLEROTIC

PLAQUE

Plaque architecture may be modified by statin treatment due not only to modification of cholesterol concentrations, but also by altering the concentrations of triglycerides and high density lipoproteins (HDL).

There is ample evidence to support the benefits of cholesterol reduction for all patients. In the last few months data have become available which explore the role of statins in modifying patients' lipid profiles. In a randomised, double blind, multicentre study, patients with clear evidence of vascular insufficiency but who had average LDL cholesterol, low HDL, and a slight elevation in triglycerides, received gemfibrozil or placebo and were followed for five years. ${ }^{9}$

The results showed that the patients' cholesterol concentrations did not change-LDL cholesterol concentrations were identical in the treatment and placebo arms of the study. However, the patients' HDL concentrations rose in response to treatment and triglyceride concentrations fell but still remained within the normal range (fig 3). Despite these subtle changes there was a $22 \%$ benefit in terms of fatal and non-fatal myocardial infarction with no effect at all on cancer rates.

Lipid lowering should not be aimed solely at reducing LDL, but also at producing a range of changes including lowering triglycerides and raising $\mathrm{HDL}$.

\section{The future}

As the population continues to age, statins will be prescribed more frequently among elderly patients. Polypharmacy and drug interactions will therefore become increasingly important issues. As one of the major pathways for drug detoxification is the cytochrome P450 system in the liver, the ideal statin would have a different metabolic pathway. There are already some statins available and others under development that have these properties.

\section{Trial acronyms}

CARE: Cholesterol and Recurrent Events Trial

LIPID: Long Term Intervention with Pravastatin in Ischaemic Disease

4S: Scandinavian Simvastatin Survival Study

TexCAPS: Texas Coronary Atherosclerosis Prevention Study

WOSCOPS: West of Scotland Coronary Prevention Study

Finally, the possibility of statin treatment working through a mechanism other than the reduction of cholesterol should be explored.

1 American Heart Association. International 1998 heart and stroke statistical update. Dallas, Texas: American Heart Association, 1998.

2 National Cholesterol Education Program. Second report of the expert panel on detection, evaluation, and treatment of the expert panel on detection, evaluation, and treatment of

3 Wood D, De Backer G, Faergeman O, et al. Prevention of coronary heart disease in clinical practice: recommendations of the second joint task force of European and other tions of the second joint task force of European and other societies on

4 The Scandinavian Simvastatin Survival Study (4S) Study Group. Randomised trial of cholesterol lowering in 4444 patients with coronary heart disease: the Scandinavian simvastatin survival study (4S). Lancet 1994;344:1383-9.

5 The Long-Term Intervention with Pravastatin in Ischaemic Disease (LIPID) Study Group. Prevention of cardiovascular events and death with pravastatin in patients with coronary heart disease and a broad range of initial cholesterol levels. N Engl f Med 1998;339:1349-57.

6 Sacks FM, Pfeffer MA, Moye LA, et al. The effect of pravastatin on coronary events after myocardial infarction in recurrent events trial investigators. N Engl f Med 1996;335: 1001-9.

7 Shepherd J, Cobbe SEM, Ford I, et al for The West of Scotland Coronary Prevention Study Group. Prevention of coronary heart disease with pravastatin in men with hypercholesterolemia. N Engl f Med 1995;333:1301-7.

8 Downs JR, Clearfield M, Weis S, et al. Primary prevention of acute coronary events with lovastatin in men and women with average cholesterol levels: results of AFCAPS/ TexCAPS. Air Force/Texas coronary atherosclerosis prevention study. FAMA 1998;279:1615-22.

9 Rubins HB, Robins SJ, Collins D, et al. Gemfibrozil for the secondary prevention of coronary heart disease in men with low levels of high-density lipoprotein cholesterol. Veterans Affairs high-density lipoprotein cholesterol intervention trial study group. N Engl F Med 1999; 341:410-18. 